\title{
SISTEM PREDIKSI JUMLAH PENGUNJUNG WISATA WEGO KEC.SUGIO KAB.LAMONGAN MENGGUNAKAN METODE FUZZY TIME SERIES
}

\author{
Fitri Rohmawati $^{1)}$, Ghofar Rohman ${ }^{2)}$, Siti Mujilahwati ${ }^{3)}$ \\ ${ }^{1)}$ Mahasiswa Program Studi Teknik Informatika, Fakultas Teknik, Universitas Islam Lamongan \\ ${ }^{2,3)}$ Dosen Program Studi Teknik Informatika, Fakultas Teknik, Universitas Islam Lamongan \\ Jl.Veteran No. 53 A Lamongan \\ Telp. (0322) 324706 \\ E-mail: Fitrirohma@gmail.com ${ }^{1}$,m.ghofarrohman@unisla.ac.id ${ }^{2}$,meodjee@gmail.com ${ }^{3}$
}

\begin{abstract}
Lamongan Regency has enormous potential in tourism development. The need for tourist attractions in Lamongan Regency is in great demand makes the government certainly needs to observe it, the government in this case refers to the Tourism Departmentin Lamongan Regency to maintain and take care of these tourist attractions in order to provide comfort for the visitors. Realized or not, the number of visitors who come to a tourist attraction depends on the convenience of the place for the visitors. Wegois one of the tourist attractions in Lamongan Regency that is very potential in an effort to increase the economic growth in Lamongan Regency that should get the special attention.The rate of tourists who visit Wego increases on certain days.Seeing that potential, the professional handling by the manager of the tourist attraction must be done in an effort to achieve the target company. Related to the problem, then the manager must be able to predict and set the target number of Wego tourist attraction's visitors for the next period.
\end{abstract}

Keywords: Lamongan, Wego, Prediction System, Mysql

\section{PENDAHULUAN}

Seiring dengan perkembangan zaman, manusia modern telah menemukan cara atau metode peramalan yang lebih rasional yaitu berdasarkan data historis. Dengan didukung oleh perkembangan dunia statistik, manusia mulai mengembangkan metode tersebut. Disadari atau tidak manusia modern pada abad ini lebih menyuukai berpikir kuantitatif. Sehingga beberapa keputusan-keputusan yang diambil harus atas dasar analisis. Hal ini mengakibatkan peranan dunia statistik makin besar untuk pengambilan keputusan karena dengan mengetahui perkiraan apa yang akan terjadi di masa yang akan datang keputusan akan lebih mudah diambil.

Forecast atau peramalan merupakan salah satu unsur yang sangat penting dalam pengambilan keputusan. Pada dasarnya peramalan dilakukan berdasarkan pada data histories yang dianalisis menggunakan cara-cara tertentu. Data histories tersebut dikumpulkan, dianalisis dan dipelajari untuk kemudian dihubungkan dengan perjalanan waktu.

Tingkat kebutuhan akan wisata yang tinggi tentu perlu dicermati oleh pemerintah dalam hal ini Dinas Pariwisata Kabupaten Lamongan untuk menjaga dan merawat obyek wisata tersebut guna memberikan kenyamanan bagi para pengunjung. Tingkat kunjungan obyek wisata Wego meningkat pada hari-hari tertentu. Melihat potensi itu maka penanganan secara profesional oleh pihak yang mengelola obyek wisata harus dilakukan.

Teknik peramalan dapat dilakukan dalam memprediksi jumlah pengunjung obyek wisata dengan mempelajari pola data pengunjung terdahulu. Metode peramalan yang digunakan dalam peramalan ini adalah Analisis Runtun Waktu Fuzzy. Berdasarkan uraian pada latar belakang masalah tersebut, maka perumusan masalah yaitu: Bagaimana membuat perhitungan prediksi jumlah pengunjung wisata Wego Kec.Sugio Kab.Lamongan menggunakan metode Fuzzy time series dan Bagaimana cara membuat Aplikasi Sistem Prediksi Jumlah Pengunjung Wisata Wego Kec.Sugio Kab.Lamongan Menggunakan Metode 
Fuzzy Time Series.

Prediksi adalah suatu proses memperkirakan secara sistematis tentang sesuatu yang paling mungkin terjadi di masa depan berdasarkan informasi masa lalu dan sekarang yang dimiliki, agar kesalahannya (selisih antara sesuatu yang terjadi dengan hasil perkiraan) dapat diperkecil. Prediksi tidak harus memberikan jawaban secara pasti kejadian yang akan terjadi, melainkan berusaha untuk mencari jawaban sedekat mungkin yang akan terjadi. (Herdianto, 2013).

Wisata Edukasi Gondang Outbond (WEGO) pada awalnya tempat wisata ini merupakan kawasan hutan tropis yang di penuhi pohon jati, sebagian merupakan area persawahan, dan tegalan.Pengolahan lahan pertanian di lokasi tersebut menjadi penghasilan utama bagi masyarakat di sekitar kawasan Wego Lamongan tersebut. Menariknya kawasan ini berdekatan dengan waduk gondang yang merupakan salah satu tempat wisata alam yang fenomenal di kota yang akrab disapa dengan Jaka Tingkir ini. Dari lokasi tampak indah pemandangan air waduk gondang yang dikelilingi dengan ratusan pepohonan hijau serta persawahan yang akan menjadi penandangan alam yang sangat menarik (Yunfa,2016)

Fuzzy logic jika di atau dalam bahasa Indonesia logika Fuzzy adalah teknik/metode yang dipakai untuk mengatasi hal yang tidak pasti pada masalah - masalah yang mempunyai banyak jawaban. Pada dasarnya Fuzzy logic merupakan logika bernilai banyak/multivalued logic yang mampu mendefinisikan nilai diantara keadaan yang konvensional seperti benar atau salah, ya atau tidak, putih atau hitam dan lain-lain. Penalaran Logika Fuzzy memnyediakan cara untuk memahami kinerja system dengan cara menilai input dan output system dari hasil pengamatan. Logika Fuzzy menyediakan cara untuk menggambarkan kesimpulan pasti dari informasi yang samar-samar, ambigu dan tidak tepat. Fuzzy logic Pertama kali dikembangkan oleh Lotfi A. Zadeh tahun 1965. Keunggulan dari Logika Fuzzy adalah konsep logika Fuzzy mudah dimengerti, memiliki Logika yang fleksibel, Logika Fuzzy mampu memodelkan fungsi-fungsi nonlinear yang sangat kompleks (Nugroho, 2016).

Fuzzy time series adalah sebuah konsep baru yang diusulkan oleh Song dan Chissom berdasarkan teori fuzzy set dan konsep variabel linguistik dan aplikasinya oleh Zadeh. Fuzzy time series digunakan untuk menyelesaikan masalah peramalan yang mana data historis adalah nilai-nilai linguistik.Misalnya, dalam masalah peramalan, data historis tidak dalam bentuk angka real, namun berupa data linguistik. Dalam hal ini, tidak ada model time series konvensional yang dapat diterapkan, akan tetapi model fuzzy time series dapat diterapkan dengan lebih tepat. Perbedaan utama antara fuzzy time series dan konvensional time series yaitu pada nilai yang digunakan dalam peramalan, yang merupakan himpunan fuzzy dari bilanganbilangan real atas himpunan semesta yang ditentukan (Fauziah, 2016).

Microsoft Visual Basic .NET adalah sebuah alat untuk mengembangkan dan membangun aplikasi yang bergerak di atas sistem .NET Framework, dengan menggunakan bahasa BASIC. Dengan menggunakan alat ini, para programmer dapat membangun aplikasi Windows Forms, Aplikasi web berbasis ASP.NET, dan juga aplikasi command-lineNET. Visual Basic .NET merupakan sebuah bahasa pemrograman yang mendukung fitur "Bahasa Pemrograman Berorientasi Objek" secara penuh, karena memang didukung oleh arsitektur Microsoft .NET Framework, yang mengandung kombinasi dari Common Language Runtime dan Base Class Library. aplikasi web berbasis database secara mudah. Program XAMPP banyak diaplikasikan dan digunakan oleh kalangan pengguna komputer di bidang pemrograman web.XAMPP merupakan software gratis.

\section{METODE PENELITIAN}

Pada metode penelitian ini terdapat metode penelitian yaitu:

1. Analisis desain sisem

2. Analisis desain program 


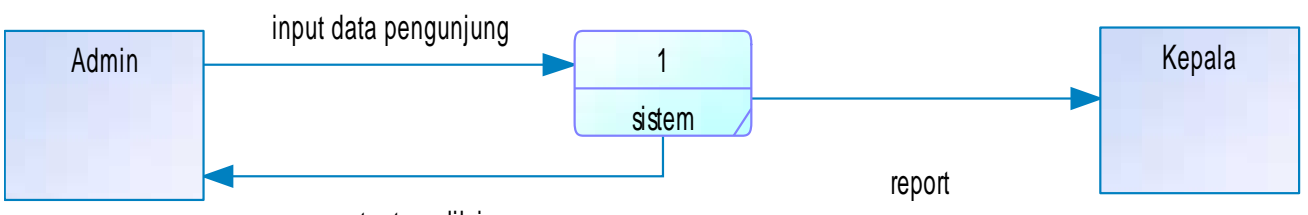

output prediksi

Gambar 1. Diagram Konteks

Pada diagram konteks Gambar 1 tersebut mengelola seluruh data dan kepala yang terdapat 2 entitas yaitu admin yang menerima laporan.

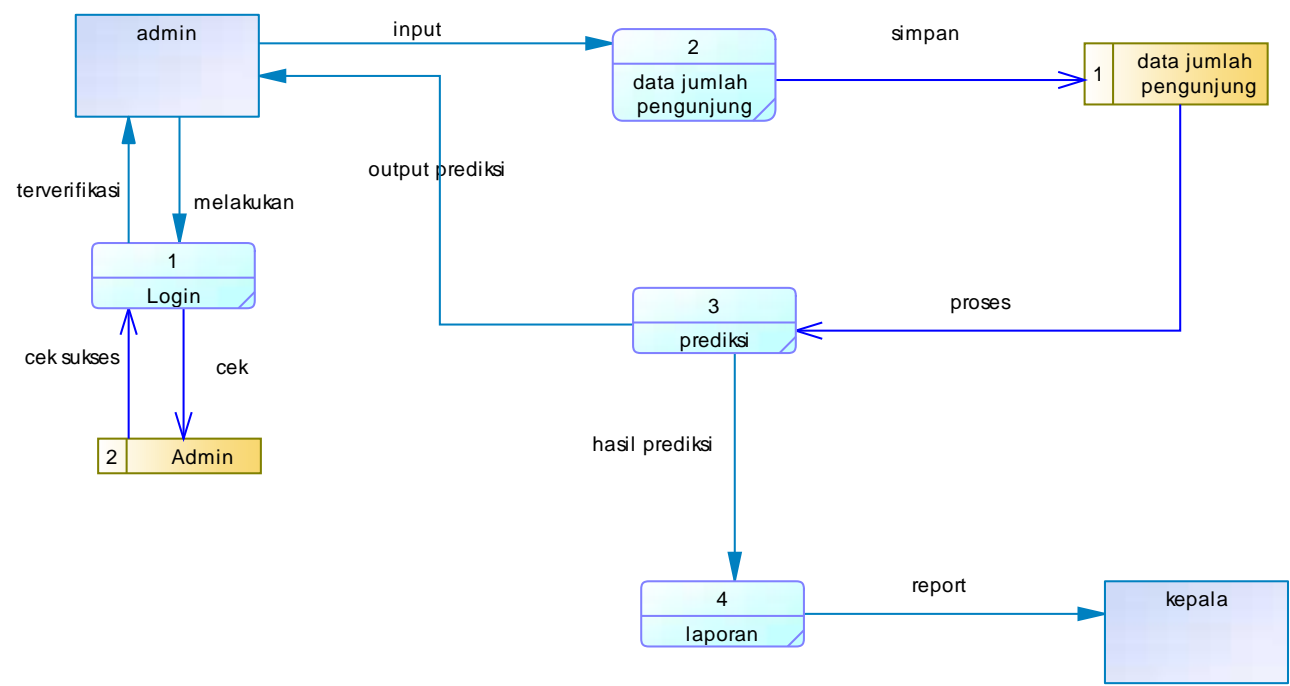

Gambar 2. DFD Level 0 Sistem Prediksi

Dari Gambar 2 dfd level 0 di atas maka disimpulkan bahwa pada DFD tersebut terdapat 3 proses yaitu:

1. Admin menginpukan data jumlah pengunjung ke database.
2. Admin menjalankan Sistem Prediksi.

3. Kepala mendapat output report dari system 
Yogyakarta, 10 Maret 2012

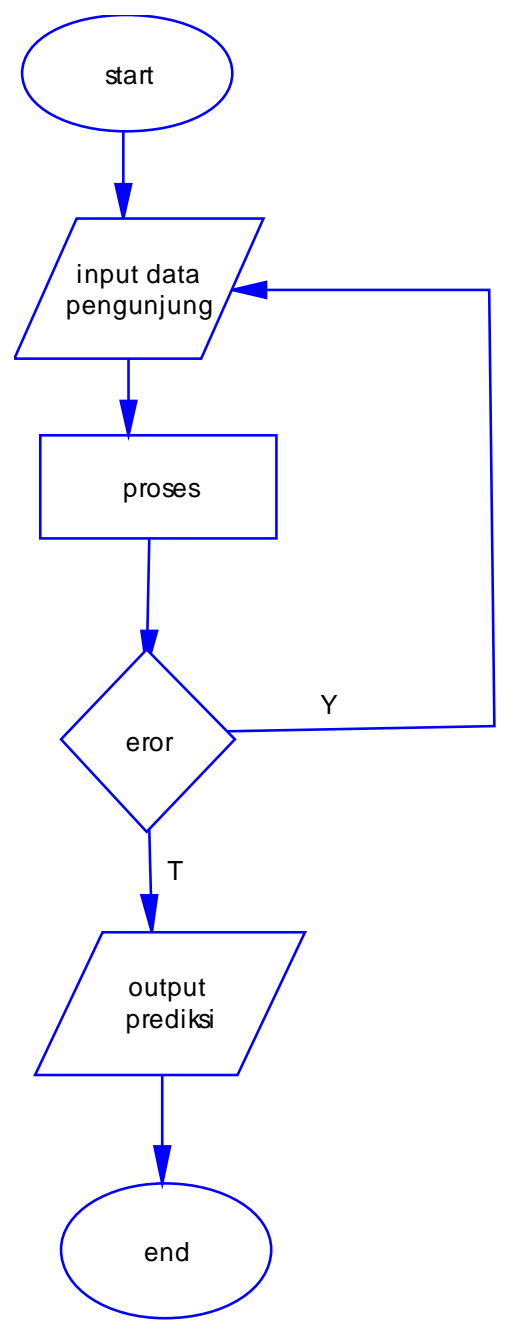

Gambar 3. Flowchart Sistem Prediksi

Berdasarkan gambar 3 flowchart di atas dapat dijabarkan sebagai berikut. Start program, input data pengunjung kemudian melakukan proses data training yang selanjutnya dilakukan jika memenuhi criteria maka akan keluar hasil berupa output hasil prediksi dan jika tidak memenuhi maka proses kembali dilakukan dari awal.

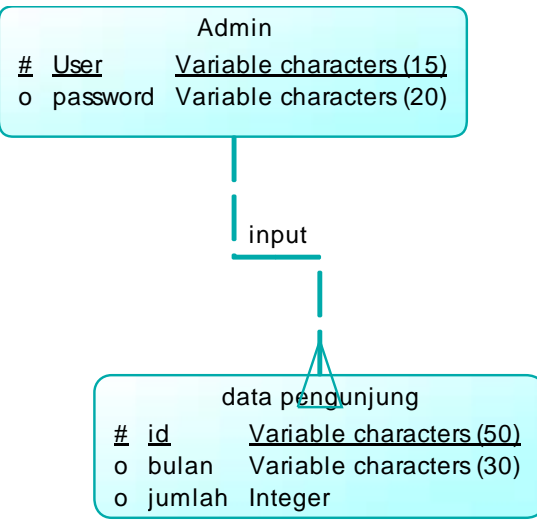

Gambar 4. CDM Sistem Prediksi

Dari gambar 4 CDM di atas maka disimpulkan bahwa pada CDM tersebut terdapat entitas yaitu admin dan data pengunjung yang akan dip roses sistem. 


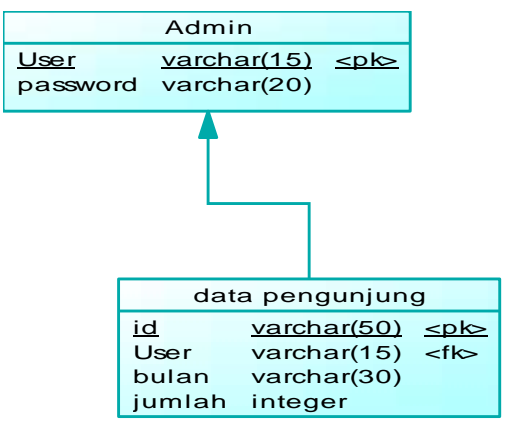

Gambar 5. PDM Sistem Prediksi

Dari gambar di atas maka disimpulkan bahwa pada CDM tersebut terdapat 2 entitas yaitu:

1. Admin

2. Data pengunjung

Perhitungan Manual

Langkah 1. Input data Pengunjung

Langkah 2. Partisikan himpunan semesta $U$ menjadi beberapa interval $u_{1}, u_{2}, u_{3}, \ldots, u_{n}$

Menjumlahkan tiap bulan untuk mempermudah perhitungan.

Tabel 1. Data Aktual Partisi Pengunjung

\begin{tabular}{ccc}
\hline No & Data perbulan & Data aktual \\
\hline 1 & November & 13558 \\
2 & Desember & 14254 \\
3 & Januari & 30125 \\
4 & Februari & 13124 \\
5 & Maret & 14600 \\
6 & April & 14383 \\
Jumlah & & 100044 \\
\hline
\end{tabular}

Langkah 3. Definisikan universe of discourse (mencari nilai minimal dan maksimal)

Nilai minimal dan maksimal dari data aktual berdasarkan nilai-nilai tersebut maka universe of discourse $U$ dapat didefinisikan sebagai $\mathrm{U}=[13124,30125]$

Langkah 4. Menghitung interval dan himpunan fuzzy

Menghitung nilai interval himpunan fuzzy dengan mencari rata-rata selisih:

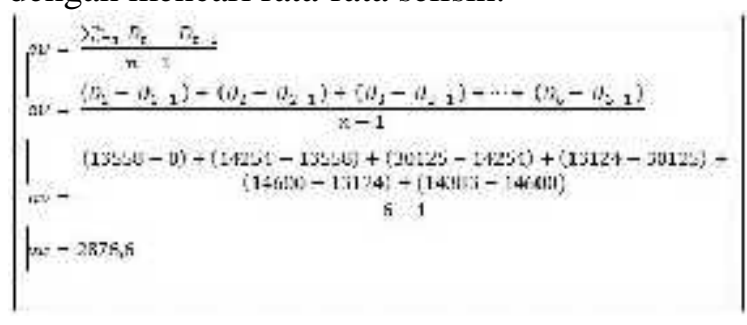

Diperoleh $t=$ rata rata selisih sebesar 2876,6 ntuk memperoleh besar basis

$$
\begin{aligned}
& R=\frac{a v}{2} \\
& B-\frac{2876,6}{2} \\
& B=1438,3
\end{aligned}
$$

maka nilai rata-rata dibagi dua dan hasilnya adalah 1438,3. Jadi basis yang digunakan adalah 1000. Selanjutnya diperoleh jumlah interval yaitu 2 dengan perhitungan sebagai berikut:

$$
\begin{aligned}
& m-\frac{D_{\text {max }}+V_{1}-V_{\min }+D_{2}}{b} \\
& m-\frac{30125}{13558 \quad 13124} \\
& m=16,305
\end{aligned}
$$

Dan diperoleh Himpunan fuzzy sebagai berikut:

Tabel 2. Hasil Himpunan Fuzzy

\begin{tabular}{rr}
\hline \multicolumn{2}{c}{ Himpunan Fuzzy } \\
\hline A1 & $(13558,14558)$ \\
A2 & $(14558,15558)$ \\
A2 & $(15558,16558)$ \\
A3 & $(16558,17558)$ \\
A4 & $(17558,18558)$ \\
A5 & $(18558,19558)$ \\
A6 & $(19558,20558)$ \\
A7 & $(20558,21558)$ \\
A8 & $(21558,22558)$ \\
A9 & $(22558,23558)$ \\
A10 & $(23558,24558)$ \\
A11 & $(24558,25558)$ \\
A12 & $(25558,26558)$ \\
A13 & $(26558,27558)$ \\
A14 & $(27558,28558)$ \\
A15 & $(28558,29558)$ \\
A16 & $(29558,30558)$ \\
\hline
\end{tabular}

Langkah 5. Fuzzifikasi data aktual Berdasarkan himpunan fuzzy di atas maka akan diperoleh fuzzifikasi data-data aktual seperti pada tabel di bawah ini: 
Tabel 3. Hasil Fuzzifikasi Data Aktual

\begin{tabular}{rclc}
\hline Data & Jumlah & interval & Fuzzifikasi \\
\hline 1 & 13558 & $(13558,14558)$ & A1 \\
2 & 14254 & $(13558,14558)$ & A1 \\
3 & 30125 & $(29558,30558)$ & A16 \\
4 & 13124 & $(13558,14558)$ & A1 \\
5 & 14600 & $(14558,15558)$ & A2 \\
6 & 14383 & $(14558,15558)$ & A2 \\
\hline
\end{tabular}

Langkah 6. Menentukan Fuzzy Logical Relation

Berdasarkan tabel di atas diperoleh fuzzy logical relation yaitu:

$$
\begin{aligned}
& \mathrm{A} 1 \rightarrow \mathrm{A} 1 \\
& \mathrm{~A} 1 \rightarrow \mathrm{A} 1 \\
& \mathrm{~A} 1 \rightarrow \mathrm{A} 16 \\
& \mathrm{~A} 16 \rightarrow \mathrm{A} 1 \\
& \mathrm{~A} 1 \rightarrow \mathrm{A} 2 \\
& \mathrm{~A} 2 \rightarrow \mathrm{A} 2
\end{aligned}
$$

Langkah 7. Menentukan fuzzy logical relation group

Dari hasil fuzzy logical relation kemudian menentukan fuzzy logic relation group,yaitu mengambil nilai dari jarak relation:

Tabel 4. Hasil Fuzzy logical relation group

\begin{tabular}{ccc}
\hline No & Relation & Nilai \\
\hline 1 & A1 $\rightarrow$ A1 & 13558 \\
2 & A1 $\rightarrow$ A1 & 14254 \\
3 & A1 $\rightarrow$ A16 & 2774 \\
4 & A16 $\rightarrow$ A1 & 2703 \\
5 & A1 $\rightarrow$ A2 & 13862 \\
6 & A2 $\rightarrow$ A2 & 14383 \\
\hline
\end{tabular}

Langkah 8.Menghitung hasil peramalan Menghitung menggunakan $\left\{D \times \frac{\text { bass } B}{\text { basıs } m}\right\}$ maka akan mendapat hasil sebagai berikut:

Tabel 5. Hasil Peramalan

\begin{tabular}{cc}
\hline Data & Hasil peramalan \\
\hline 1 & 13620 \\
2 & 14316 \\
3 & 2836 \\
4 & 2765 \\
5 & 13924 \\
6 & 14445 \\
Jumlah & 61906 \\
\hline
\end{tabular}

Data tahun 2016 yaitu 100044 pengunjung, sementara hasil prediksi 61906. Maka jumlah pengunjung Wego diperkirakan turun 38138 .

\section{HASIL DAN PEMBAHASAN}

Pembahasan fitur merupakan kajian yang dilakukan untuk memberikan gambaran utama aplikasi. Adapun komponen-komponen utama yang ada aplikasinya adalah sebagai berikut:

1. Menu login berfungsi untuk masuk kedalam proses aplikasi agar bisa menghapus,mengedit dan menambah data yang akan diperlukandengan memasukkn username dan password yang tepat admin akan masuk ke menu utama.

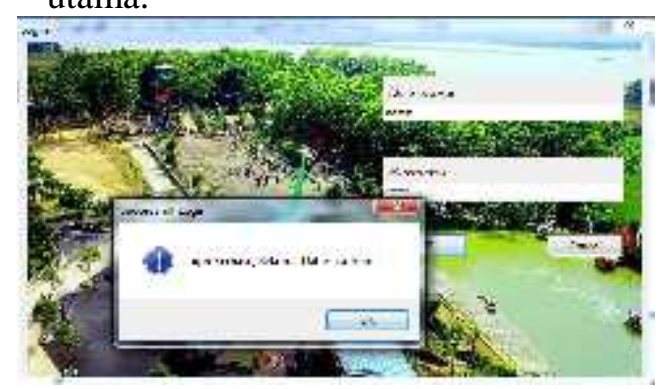

Gambar 6. Menu Login

2. Menu Utama mempunyai 5 sub menu yaitu input data pengunjung, prediksi, report, setting dan about.

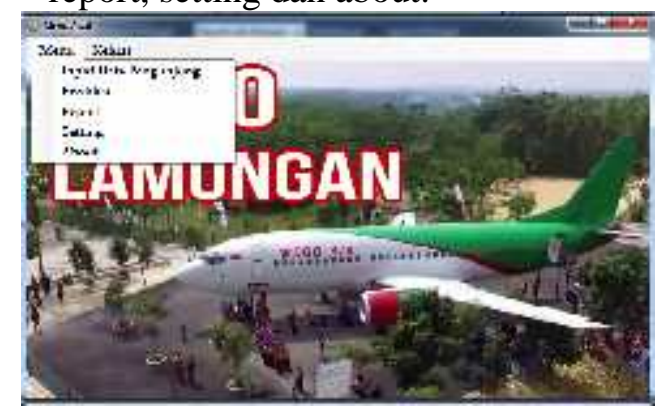

Gambar 7. Menu Utama

3. Form input data pengunjung

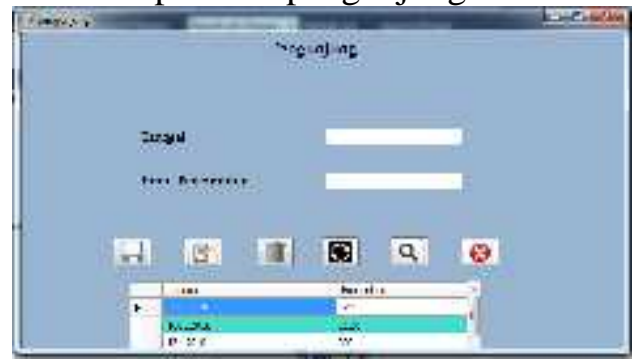

Gambar 8. Input Data Pengunjung 
Form input data pengunjung ini memiliki beberapa fungsi tombol yaitu:

- Simpan: digunakan untuk menyimpan data yang akan ditambahkan

- Ubah: digunakan untuk mengubah data yang sudah ada

- Hapus: digunakan untuk menghapus data

- Reset: digunakan untuk mengosongkan kembali kolom

- Cari : digunakan untuk mencari data

- Keluar: keluar dari form

4. Form Setting

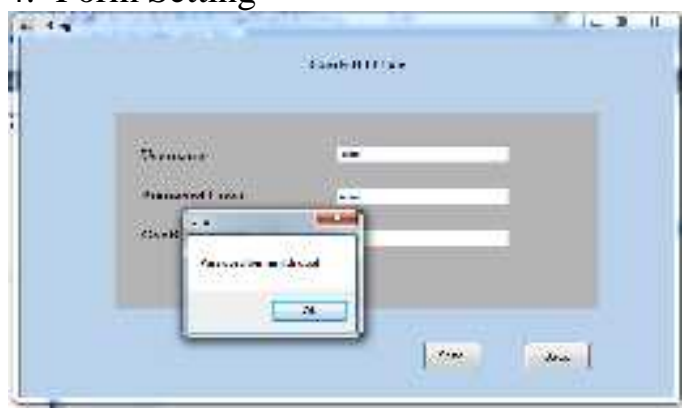

Gambar 9. Setting User

Form ini memiliki tombol save yang memiliki fungsi menyimpan/mengganti password ke baru dan tombol back untuk kembali ke menu utama.

5. Form Prediksi

Pada form prediksi ini memiliki beberapa proses, yang pertama adalah tampilan awal:

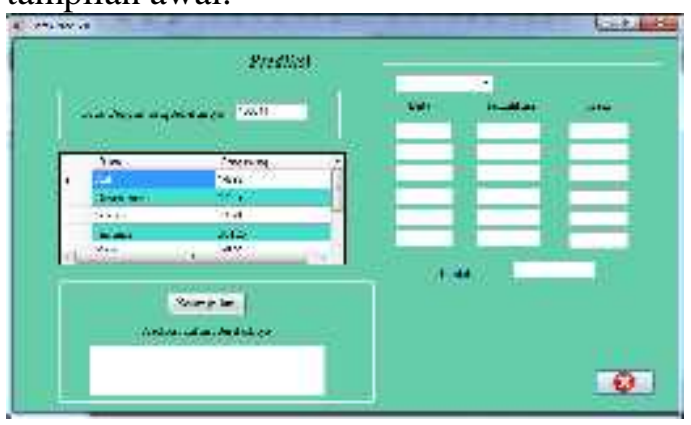

Gambar 10. Tampilan Awal

Ke dua, adalah tampilan setelah fuzzifikasi dan hasil muncul maka akan muncul data jumlah:

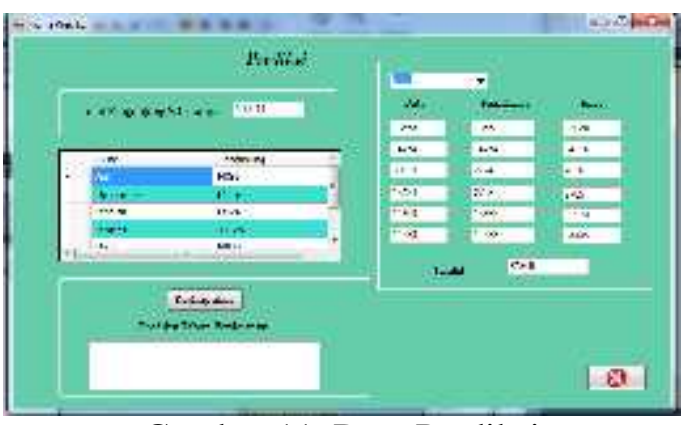

Gambar 11. Data Prediksi

Yang terakhir setelah mengklik tombol hasil prediksi maka hasil prediksi akan muncul seperti berikut:

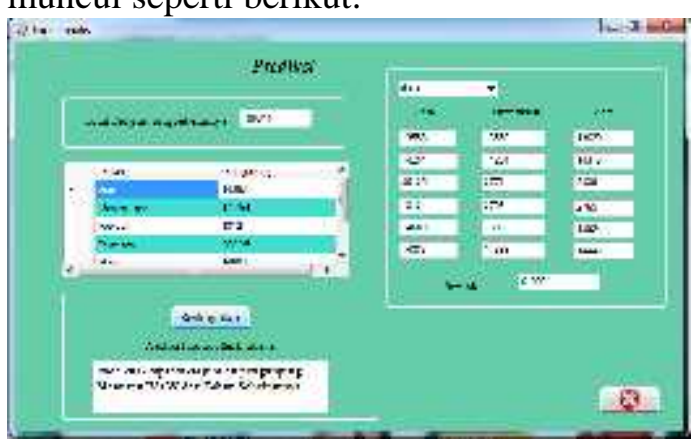

Gambar 12. Hasil Predksi

\section{KESIMPULAN}

Setelah melalui beberapa proses berdasarkan analisis, desain, implementasi perangkat lunak dan pembahasan, maka dapat ditarik beberapa kesimpulan yaitu: Metode Fuzzy Time Series dapat diterapkan di Visual Basic.Net dengan baik. Perangkat lunak Sistem Prediksi Jumlah Pengunjung Wisata Wego Kec.Sugio Kab.Lamongan menggunakan metode Fuzzy Time Series telah berhasil di jalankan dan dapat mempermudah proses penyimpanan data pengunjung.

\section{REFERENSI}

[1] Fauziah, Normalita, 2016, Peramalan Mengunakan Fuzzy Time Series Chen ,UNIMUS, Vol 4, http://jurnal.unimus.ac.id/index.php/sta tistik/article/view/2234 (diakses tanggal 22-maret 2017)

[2] Herdianto, 2013, Metode Prediksi, http://digilib.mercubuana.ac.id/manage r/n@file_skripsi/Isi2200481714326.pd f (diakses tanggal 22-maret 2017) 
[3] Nugroho,Kristiawan, 2016, Model Analisis Prediksi Menggunakan Metode Fuzzy Time Series

http://amikjtc.com/jurnal/index.php/jur nal/article/download/91/85 (diakses tanggal 19-maret 2017)
[4] Yunfa,Indira Ningtias ,2016, WEGO Lamongan, Wisata Edukatif yang Unik Sekaligus Menarik.

https://alimustikasari.com/wego-

lamongan -wisata-edukatif-yang-uniksekaligus- menarik. (diakses tanggal 22-maret 2017) 